\title{
An Integrating Finite Element Method and Multi- body Simulation for Drive Systems Analysis
}

\author{
Wasan Suwannahong ${ }^{1,2}$ and Chakrit Suvanjumrat ${ }^{1,2, *}$ \\ 1 Department of Mechanical Engineering, Faculty of Engineering, Mahidol University, Nakhon Pathom \\ 73170, Thailand \\ 2 Laboratory of Computer Mechanics for Design (LCMD), Department of Mechanical Engineering, Faculty \\ of Engineering, Mahidol University, Nakhon Pathom 73170, Thailand \\ *E-mail: chakrit.suv@mahidol.ac.th
}

\begin{abstract}
Roller chain and sprockets are an important component of the drive system in production lines of any industries. Many problems which concerned for damage of roller chain and sprockets would break down the producing process. To understand every failure behavior might be used a long time of experience in production lines. Furthermore, some phenomena of failure cases for roller chain and sprockets were unpredictable by an analytic method. This research aimed to propose installed cases of the roller chain and sprocket by the modeling technique. The new method for simulation of drive system was employed to analyze roller chain and a sprocket. The finite element method was used to simulate the behavior of parts that might be damaged by integrating with the multi-body system of rigid parts in the driving system. The integrating simulation would explain any installed cases of roller chain and a sprocket distinctively. Particularly, simulation results in many forms the roller chain which wrapped a sprocket would be good examples for an engineering study and design of drive system in a further work.
\end{abstract}

Keywords: Finite element method, multi-body simulation, driving system.

ENGINEERING JOURNAL Volume 21 Issue 1

Received 17 May 2016

Accepted 21 July 2016

Published 31 January 2017

Online at http://www.engj.org/

DOI:10.4186/ej.2017.21.1.221 


\section{Introduction}

The engineering design and analysis of drive system had an important role to protect failure phenomena occurring on producing components in the manufacturing process. The impact between roller chain and sprockets often reduced the life time of the drive system. The chain and sprocket design which was described in some text books [1,2] only used for supporting static loads. Nevertheless, they suggested the safety of factor for designing components under dynamic load, it was not enough to protect components from damage by the real usage condition. The roller chain might be damaged by many inappropriate usages [3]. The chain plate or link would be failed when the large tension load acted more than the maximum allowable tension. The excessive shearing load could break the pin at close to the chain plate. The failure behavior by the fatigue load had significant features on the roller chain were different from the large load. The feature of fatigue failure was that a rupture occurred in the direction almost perpendicular to the pitch line of a chain plate. The failure occurred at the center of the pin by the fatigue load which was not strong equal to the limited load of the roller chain. The roller end of the chain might be deformed or broken by the pressed force of the sprocket tooth when the tension was excessive.

The tension load which occurred in drive system was developed for studying by using formulation. The load distribution in the roller chain link and on the sprocket teeth was calculated for the rigid roller chain on a stationary rigid sprocket $[4,5]$. The equation of motion was developed to analysis the dynamic of roller chain drives such as a two-stroke diesel marine engine roller chain drive using a continuous contact force method. The contact-impact force between rollers and guide-bar of drive system could calculate according to time steps of the rollers moving on the tooth profile [6]. The analytical solution could obtain link force between two adjacent rollers and also contact force between rollers and sprocket tooth [7,8]. The profile of a sprocket which used to set a boundary for solving the equation of motion was difficult to generate close to the real sprocket profile, therefore, the error had included in calculation results. The kinematic analysis was developed to analyze roller chain drives by a four-bar mechanism. The calculation result obtained an angular position, velocity, and acceleration, respectively $[9,10]$. This method had an approximate result and could not calculate contact force between sprocket tooth and rollers. The analytical method or mathematic model might be rapidly achieved the result of drive system analysis but it was not enough to describe damage behavior of sprockets and roller chain components.

The simulation model which known as multi-body system (MBS) had preferred to design and analyze chain and sprockets $[11,12]$. The sprocket profile could generate as same as the real profile of sprockets in drive systems by computer aided design (CAD) model. The MBS was used to simulate the meshing impact force on sprocket tooth profile which was modified to improve stability of chain transmission under high speed. The tension force, friction force, and fluctuation of the chain were reduced by the improved profile [13]. Determination of stress and deformation of chains and sprockets might add finite element method (FEM) to simulate under a static or dynamic condition of contact force acting [14, 15]. The maximum stress of finite element analysis (FEA) could express fracture or failure points on sprockets and chain components. The MBS and FEM were separated to analyze roller chain and sprockets therefore it was cumbersome to understand the failure behavior of the drive systems. The dynamic analysis which expressed stress on components simultaneously during roller chain meshed on a rolling sprocket was advance to analyze the drive system. This research would present a new method to analyze drive systems. The FEM and MBS were integrated to calculate tension force, impact force, stress, deformation, and failure points on chain drive systems. Particularly, the various case studies of roller chain drive systems would be an example for the engineering study and design of a future work.

\section{Tension Force of Roller Chain Calculation}

The load distribution in the roller chain was calculated under dynamic condition following assumptions: (a) the pitch of the roller chain was equal to the pitch of a sprocket; (b) all rollers were seated on the sprocket tooth during contacting; (c) no mechanical tolerances were presented; and (d) the chain weight was negligible [4]. The component of the roller chain which was included in analytical method composed of cylindrical pins, link plates and rollers. The roller chain has pitch, link plate thickness, roller diameter, pin diameter and width of 100.00, 5.00, 52.00, 17.00 and $22.00 \mathrm{~mm}$, respectively (Fig. 1a). The roller chain which engaged with an eight teeth sprocket is illustrated by computer aided design (CAD) model in Fig. 1b. The sprocket parameters [2] are described in Table 1. The rollers and sprocket of the roller chain drive 
system have been depicted by the free body diagram as shown in Fig. 2. The sprocket was rotated in a clockwise, therefore, the tension $T_{t}$ and $T_{s}$ was the tight and slack side of chain tensions $\left(T_{i}\right)$, respectively. The rollers were in the seated position and contacted the tight flank of the sprocket tooth, therefore, tooth loads $\left(P_{i}\right)$ were acted on rollers and passed through the center of rollers. The chain rollers were numbered $\mathrm{i}$ started from the tight side to the slack side or in the counterclockwise direction. The pressure angle $(\theta)$ and articulation angle $(\alpha)$ also are described in Fig. 2. The link of the tight and slack strand made an angle $\xi$ and $\varepsilon$, respectively. The pressure angle changing by a friction angle $(\delta)$ is equivalent to the effect of friction force $\left(F_{i}\right)$. The free body diagrams of a chain roller (Fig. 3) under equilibrium consideration related to equations between tooth load and chain tension can be assumed as following:

$$
\begin{gathered}
P_{i}=\frac{T_{i-1}-T_{i} \cos \alpha}{\cos \left(\theta_{i}-\delta_{i}\right)}, i=1,2,3, \ldots, n \\
P_{i}=\frac{T_{i}-T_{i+1} \cos \alpha}{\cos \left(\theta_{i+1}-\delta_{i+1}\right)}, i=1,2,3, \ldots, n \\
P_{i}=\frac{T_{i} \sin \alpha}{\sin \left(\theta_{i}-\delta_{i}\right)}, i=1,2,3, \ldots, n \\
P_{i+1}=\frac{T_{i+1} \sin \alpha}{\sin \left(\theta_{i+1}-\delta_{i+1}\right)}, i=1,2,3, \ldots, n
\end{gathered}
$$

Therefore, the tension force on a chain link which connects to a tight link $\left(T_{t}\right)$ can calculate by Eq. (5) while the tension force of a slack link $\left(T_{s}\right)$ is calculated by Eq. (6).

where $\mu_{v}$ is the dynamic coefficient.

$$
\begin{gathered}
T_{0}=T_{t} \frac{\sin \left(\theta-\delta_{1}\right)}{\sin \left(\theta+\xi-\delta_{1}\right)} \\
T_{s}=T_{n} \frac{\sin \left(\theta-\delta_{1}\right)}{\sin \left(\theta+\varepsilon-\delta_{1}\right)} \\
\delta=\tan ^{-1}\left(\mu_{v}\right)
\end{gathered}
$$

(a)

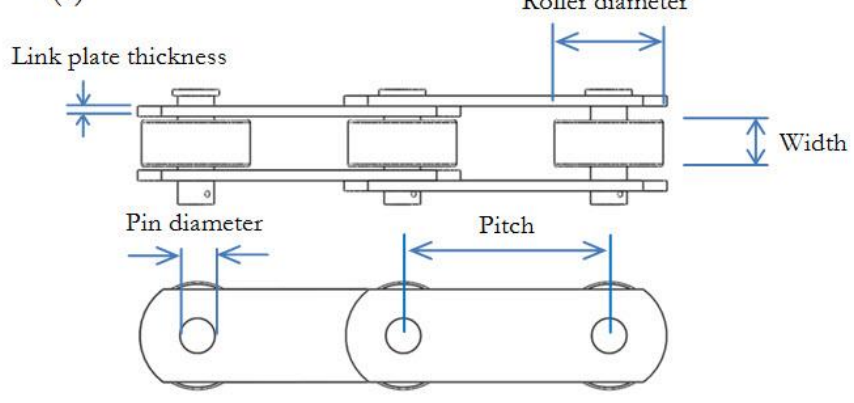

(b)

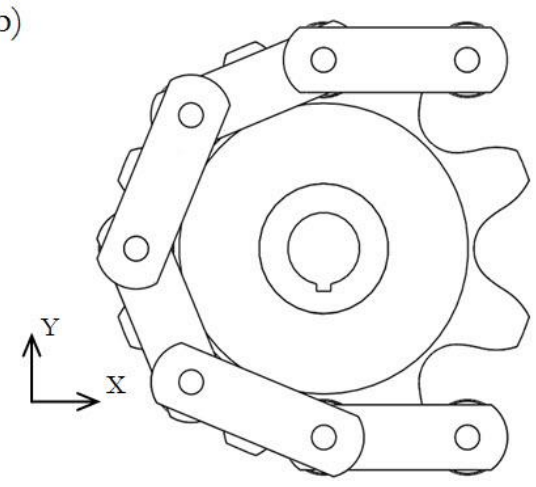

Fig. 1. CAD model description for: (a) a roller chain and (b) the roller chain drive system.

Table 1. Parameters of an eight tooth sprocket.

\begin{tabular}{lcc}
\hline Parameter & Unit & Value \\
\hline Addendum & $\mathrm{mm}$ & 20.05 \\
Dedendum & $\mathrm{mm}$ & 26.13 \\
Average pressure angle & degree & 14.50 \\
Number of teeth & - & 8 \\
Face width & $\mathrm{mm}$ & 10.00 \\
Pitch diameter & $\mathrm{mm}$ & 130.66 \\
Tooth thickness & $\mathrm{mm}$ & 43.11 \\
Width of space & $\mathrm{mm}$ & 59.50 \\
Module & $\mathrm{mm}$ & 16.33 \\
Seating curve diameter & $\mathrm{mm}$ & 52.00 \\
\hline
\end{tabular}




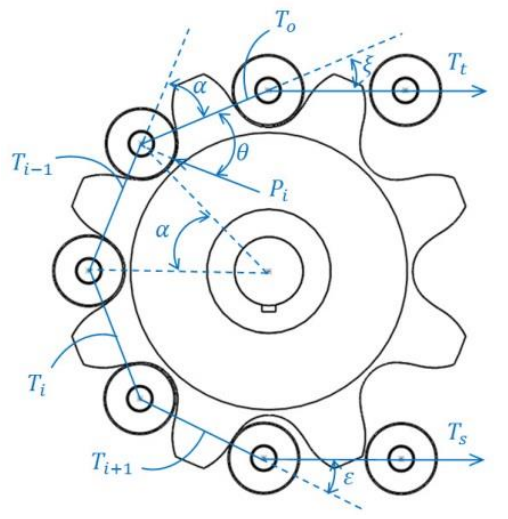

Fig. 2. Free body diagram of rollers seating on sprocket tooth.

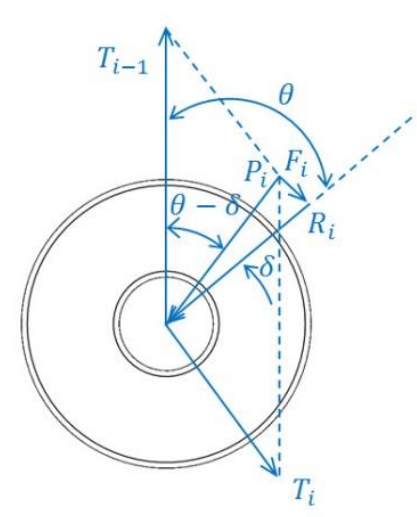

Fig. 3. Free body diagram of a dynamic chain roller.

\section{Mathematics Modeling of Flexible Body Dynamics}

The flexible body motion is governed by equation which derived with the Lagrangian equation [16] is given by the matrix form as written by:

when the Lagrangian is defined as:

$$
\frac{d}{d t}\left(\frac{\partial \boldsymbol{L}}{\partial \dot{\boldsymbol{q}}}\right)-\frac{\partial \boldsymbol{L}}{\partial \boldsymbol{q}}+\frac{\partial \boldsymbol{F}}{\partial \dot{\boldsymbol{q}}}+\left[\frac{\partial \boldsymbol{\Psi}}{\partial \boldsymbol{q}}\right]^{T}=\boldsymbol{Q}
$$

$$
\boldsymbol{L}=\boldsymbol{T}-\boldsymbol{U}
$$

where $\boldsymbol{q}$ is the vector of the generalized coordinate of the flexible bodies that consist of translational and rotational coordinates, $\boldsymbol{F}$ is the matrix of an energy dissipation function, $\boldsymbol{\Psi}$ is the matrix of the constraint function, $\boldsymbol{Q}$ is the generalized applied force vector, $\boldsymbol{L}$ is the matrix of the Lagrangian function, $\boldsymbol{T}$ is the matrix of the kinetic energy, $\boldsymbol{U}$ is the matrix of the potential energy.

The kinetic energy in the generalized mass and coordinate form can be written as:

$$
\boldsymbol{T}=\frac{1}{2} \dot{\boldsymbol{d}}^{T} \boldsymbol{M} \dot{\boldsymbol{d}}
$$

Frequently, the potential energy consists of contribution from gravity and elasticity in the quadratic form is given by:

$$
\boldsymbol{U}=\boldsymbol{U}_{g}+\frac{1}{2} \boldsymbol{d}^{T} \boldsymbol{K} \boldsymbol{d}
$$

where $\boldsymbol{U}_{g}$ is the matrix of the gravitational potential energy, $\boldsymbol{K}$ is the generalized stiffness matrix.

The damping forces depend on the generalized model velocities and assume to write by the Rayleigh's dissipation function in the matrix form as:

where $\boldsymbol{D}$ is the model damping matrix.

$$
\boldsymbol{F}=\frac{1}{2} \dot{\boldsymbol{q}}^{T} \boldsymbol{D} \dot{\boldsymbol{d}}
$$

The matrix of the constraint equation relate with flexible bodies is given by:

$$
\Psi(\boldsymbol{q}, t)=0
$$

The differential equation of flexible body motion is written by matrix form as:

$$
\boldsymbol{M} \ddot{\boldsymbol{q}}+\left(\dot{\boldsymbol{M}}-\frac{1}{2}\left[\frac{\partial \boldsymbol{M}}{\partial \boldsymbol{q}} \dot{\boldsymbol{q}}\right]^{T}\right) \dot{\boldsymbol{q}}+\boldsymbol{K} \boldsymbol{q}+\boldsymbol{f}_{g}+\boldsymbol{D} \dot{\boldsymbol{q}}+\left[\frac{\partial \boldsymbol{\Psi}}{\partial \boldsymbol{q}}\right]^{T} \lambda=\boldsymbol{Q}
$$

where $\boldsymbol{M}$ is the flexible body mass matrix, $\boldsymbol{f}_{g}$ is the generalized gravitation force vector, $\lambda$ is the Lagrange multiplier for the constraints. This dynamic governing equation of the flexible bodies will be solved by the numerical technique through MSC.Adams in this research.

The stress can be determined by using Hooke's law [17] in the matrix equation form and written as:

where

$$
\boldsymbol{\sigma}=\boldsymbol{\Phi}_{\sigma} \boldsymbol{q}
$$




$$
\boldsymbol{\Phi}_{\sigma}=\mathbf{E B} \boldsymbol{\Phi}
$$

where $\boldsymbol{\sigma}$ is the stress vector for the flexible body, $\mathbf{B}$ is a function matrix of the finite element geometry or flexible body relating strains to displacements, $\mathbf{E}$ is the stress-strain relationship based on material properties of flexible body, $\boldsymbol{\Phi}_{\sigma}$ is the ortho-normalized model stress matrix that identifies the stress component associated with each orthogonal mode shape, $\boldsymbol{\Phi}$ is the orthogonal mode shape matrix.

Likewise the stress, the strain is given by:

where

$$
\varepsilon=\Phi_{\varepsilon} q
$$

$$
\Phi_{\varepsilon}=\mathbf{B} \Phi
$$

where $\boldsymbol{\varepsilon}$ is the strain vector for the flexible body.

\section{MBS and FEM of Drive System Models}

The CAD model had been created a finite element (FE) model of the roller chain components by using 4node tetrahedron elements in MSC.Patran for analysis failure behavior. The Craig-Bampton modal synthesis method [18] in MSC.Nastran was employed to generate the model neural file (MNF) of FE model [19] to assemble links of a roller chain inside MSC.Adams. The dynamic simulation model of a roller chain was assembled by six chain links of the FE model for observing the contact force which occurred on rollers from slack side to tight side continuously. The component of the FE model of roller chain links included of cylindrical pins, link plates and rollers. The FE model of all roller chain links was constructed under the convergence test and obtained tetrahedron elements of 139,265 elements. The material properties of a roller chain model composed of elastic modulus, poisson's ratio and density which were $210 \mathrm{GPa}, 0.3$ and $7,800 \mathrm{~kg} / \mathrm{m}^{3}$, respectively. The failure of a roller chain was define by yield stress of material which was 205 MPa. The CAD model of a sprocket was defined to be a rigid body and assembled to MNF of a roller chain. The chain drive system which was generated to study failure behavior of a roller chain in MSC.Adams shows in Fig. 4. The roller chain FE model wrapped a rigid body sprocket then the tight side link and the slack link had an angle of $0^{\circ}$ (Fig. 4b). The tight side link would pull with constant velocity and the slack side would be loaded as the weight of connecting chain links. This study case, the tight chain link had a velocity of $400 \mathrm{~mm} / \mathrm{s}$ in X-direction and the slack chain link had a tension load in X-direction of $2,000 \mathrm{~N}$ as equal to a body weight of 240 chain links. The tension velocity on the tight side link made the sprocket rotated in the clockwise direction of the X-Y plane. The Gear Stiff Integrator (GSITFF) which was a solver in MSC.Adams [20] had employed to calculate dynamic response of the roller chain drive system composing of stress, strain, tension force, and impact force time history.

The sprocket model was imported to construct the FE model for failure analysis of sprocket tooth in MSC.Patran. Tetrahedron elements were still used to create the FE model of a sprocket. Fine elements would control to generate tooth of a sprocket. The number of elements under mesh convergence test was 18,865. The material properties of a sprocket composed elastic modulus of $210 \mathrm{GPa}$, poisson's ratio of 0.3 , density of $7,800 \mathrm{~kg} / \mathrm{m}^{3}$ and yield stress of $205 \mathrm{MPa}$. The same material properties as the roller chain made the distinct stress area for the strength analysis. The simulation model of the sprocket analysis was constructed conversely the roller chain analysis, therefore, all links of a roller chain was created by the rigid body. Figure 5 shows the simulation model of the sprocket analysis. The end of a roller chain had defined a velocity of $400 \mathrm{~mm} / \mathrm{s}$ and a tension load of 2,000 N (weight of 128 chain links) for a tight chain link and a slack chain link, respectively.

The roller chain and sprocket analysis were performed in a personal computer with Core-i5 CPU and RAM memory of 4 GB. 


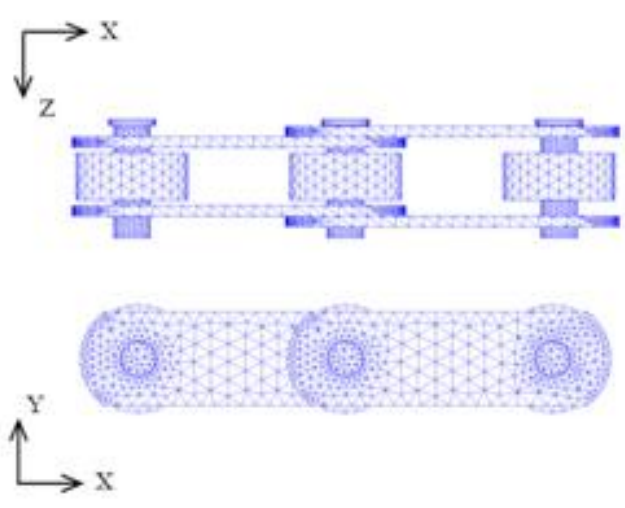

(a)

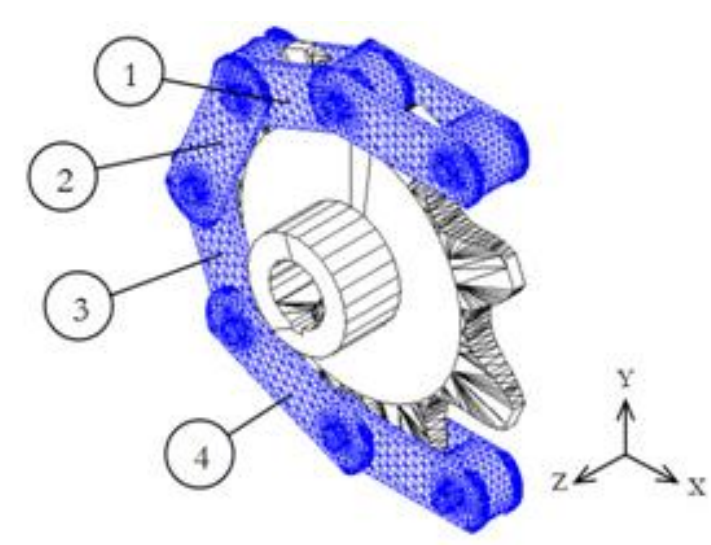

(b)

Fig. 4. The FE model of: (a) two roller chain links connection and (b) a roller chain meshing with a sprocket as a rigid body.

\section{Validation}

The dynamic tension force result by using the integrating simulation between FEM and MBS was compared with the analytical result. Comparison of tension forces $T_{1}$ which is on the first FE model of chain links on the tight side are shown in Fig. 6 by relation graphs between tension forces and time during a sprocket is rotated. The tension force $\mathrm{T}_{2}$ to $\mathrm{T}_{4}$ of the second to fourth FE model of chain links are also compared with the analytical results, respectively. The magnitude of simulated tension force at the same time of the analytic solution had an average error of $12.17 \%, 10.72 \%, 10.70 \%$ and $23.48 \%$ for $\mathrm{T}_{1}, \mathrm{~T}_{2}, \mathrm{~T}_{3}$ and $\mathrm{T}_{4}$, respectively. The errors might be the assumption of an analytic method which was negligible the chain weight. An average error of this simulation was $14.26 \%$ nevertheless the simulation result had a good agreement with the analytic result. The chain moving relates with sprocket rotating is shown by sequent images in Fig. 7. Results of the simulation could be illustrated by stress contour of a roller chain which red is maximum von Mises stress and blue is minimum von Mises stress, respectively. The maximum stress always occurred on every chain link when it rotated on twelve o'clock position of a sprocket and in every cycle of the chain link movement that was the cyclic load on the chain of the driving system. The roller chain was deformed by tension and impact force during rotation of a sprocket. The deformable chain was illustrated by color contour of strain which developed on the chain links. Figure 8 shows the sequent images of strain on the roller chain movement. The maximum strain was expressed by red and the minimum strain was blue, respectively.

The von Mises stress was developed on a FE model of a sprocket by the impact load between rollers and sprocket tooth. Figure 9 shows the image of the von Mises stress which occurs on a sprocket during rotation with angular velocity of $3.06 \mathrm{rad} / \mathrm{s}$. The von Mises stress occurred on sprocket tooth which rotated at a position that the chain link supported the maximum tension load. The chain rollers impacted and continually seated between the sprocket tooth, therefore, the maximum tension load from the roller chain was happened to defeat the pulling weight. The von Mises stress on the base of sprocket tooth fade after rollers leave of sprocket tooth and return when the sprocket tooth meshed rollers again. This stress occurred in the cyclic form and did not larger than the allowable stress. 

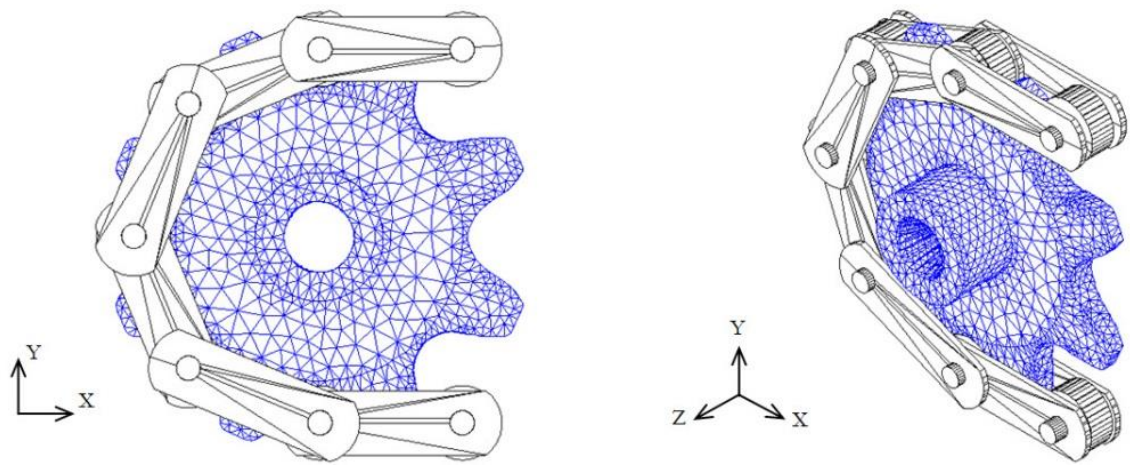

Fig. 5. The rigid body model of a roller chain meshing with the FE model of a sprocket.

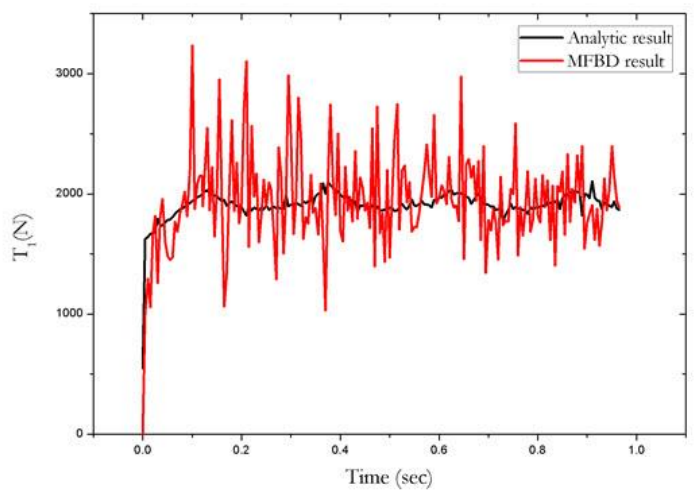

(a)

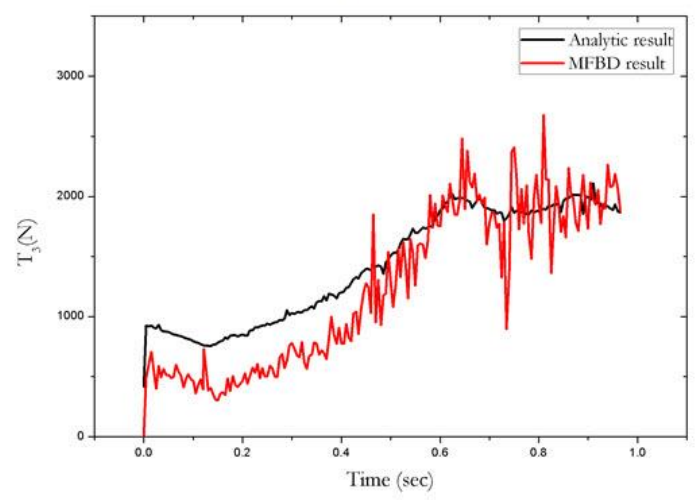

(c)

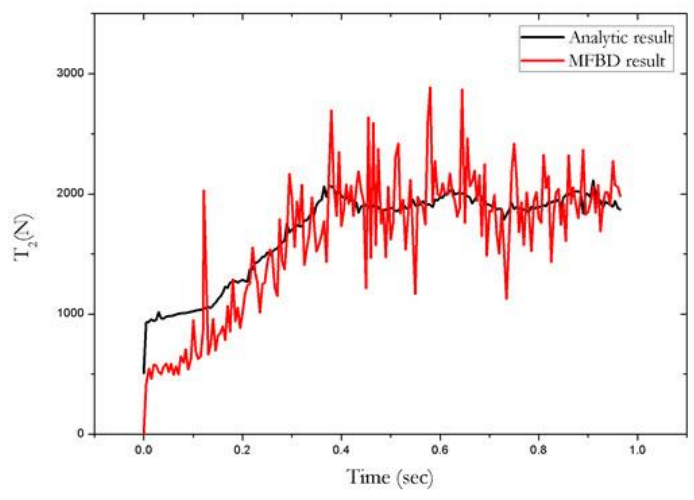

(b)

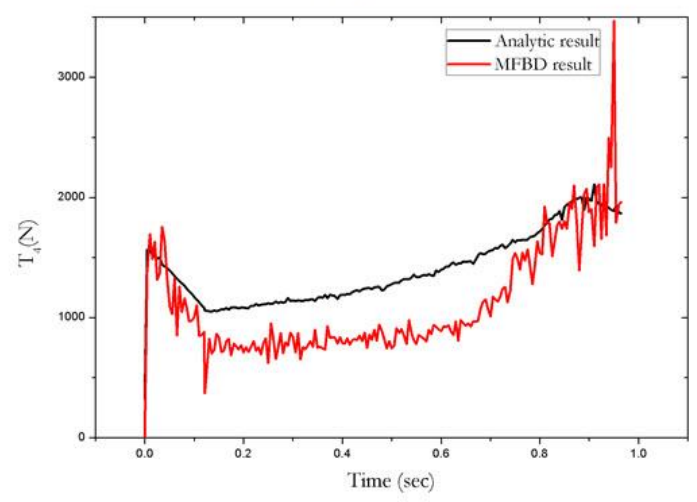

(d)

Fig. 6. The comparison of tension force occuring on chain link: (a) no. 1, (b) no. 2, (c) no. 3, and (d) no. 4. 


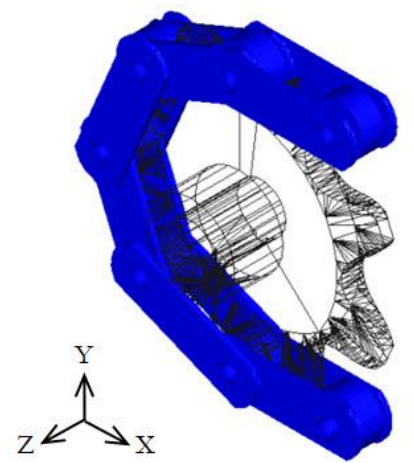

(a)

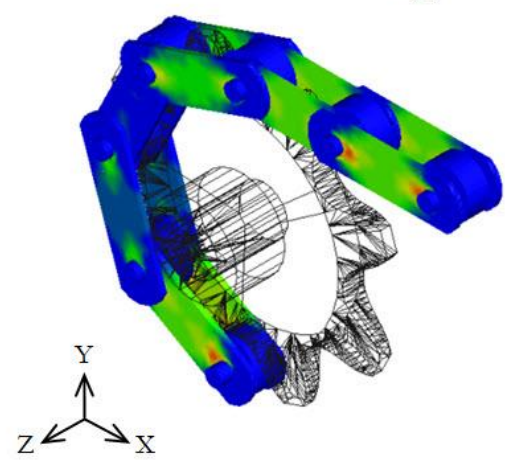

(c)
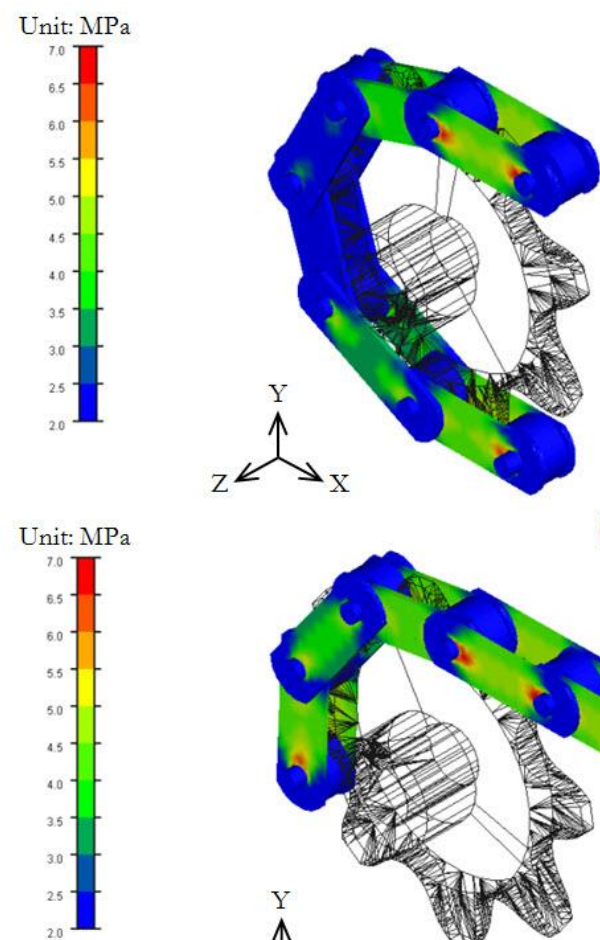

$\overbrace{x}$
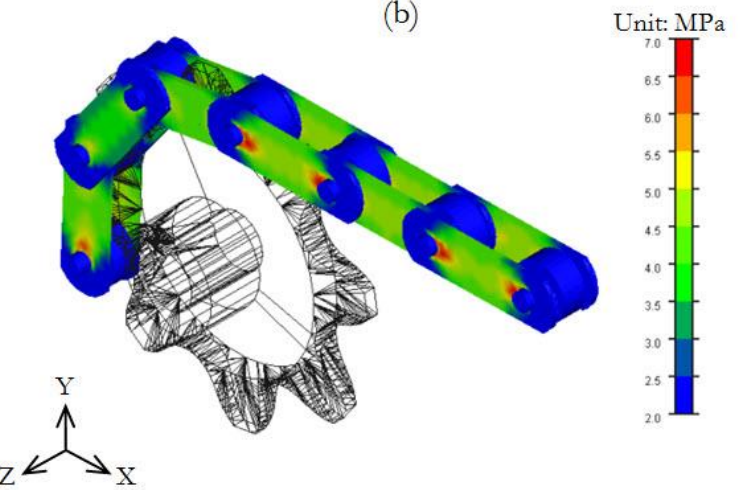

(d)

Fig. 7. The sequent images of von Mises stress developing on a roller chain of a drive system at: (a) time $=$ $0.0000 \mathrm{sec}$, (b) time $=0.0250 \mathrm{sec}$, (c) time $=0.2700 \mathrm{sec}$, and (d) time $=0.5750 \mathrm{sec}$.

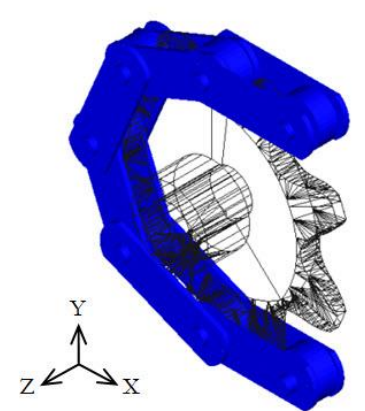

(a)

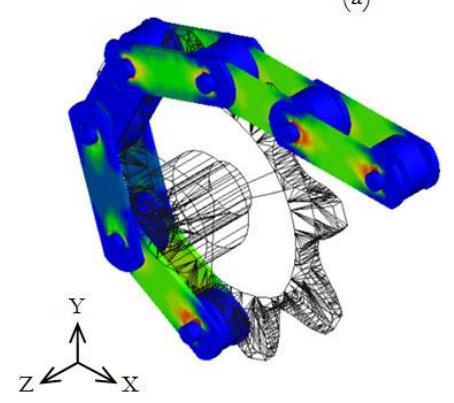

(c)
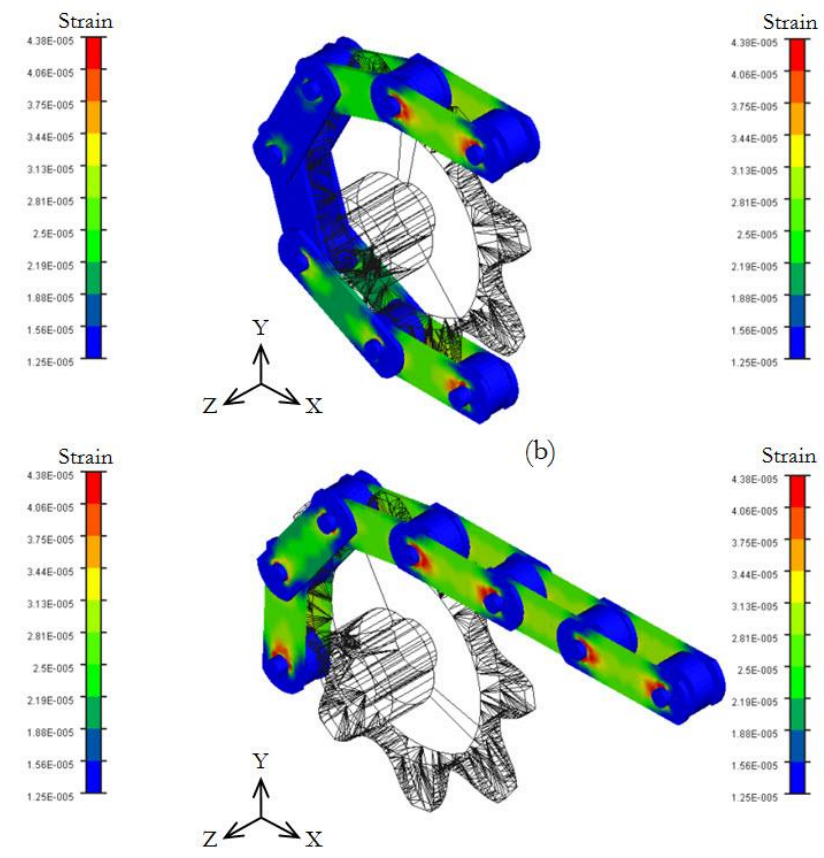

(b)

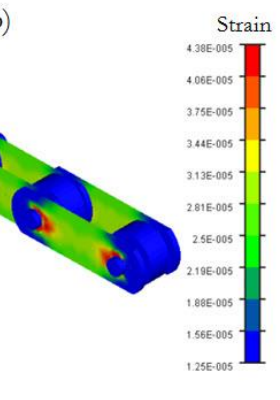

(d)

Fig. 8. The sequent images of strain developing on a roller chain of a drive system at: (a) time $=0.0000$ sec, (b) time $=0.0250 \mathrm{sec}$, (c) time $=0.2700 \mathrm{sec}$, and (d) time $=0.5750 \mathrm{sec}$. 


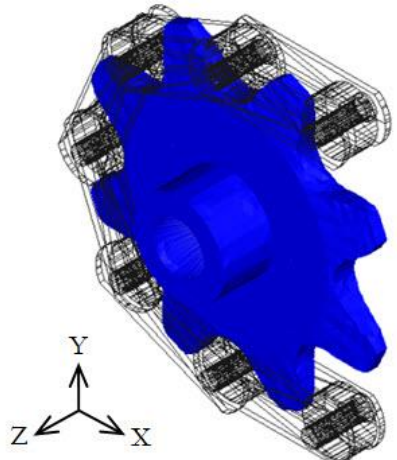

(a)

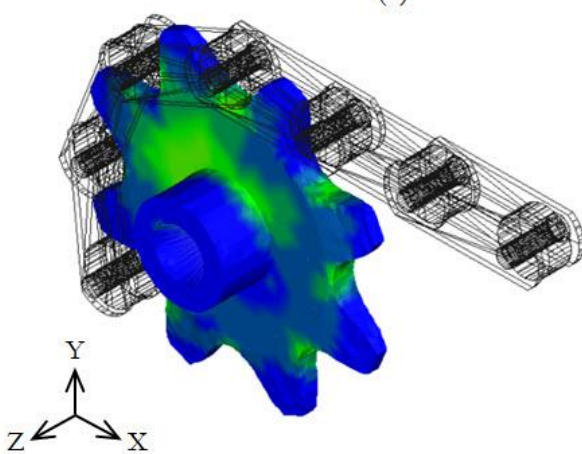

(c)
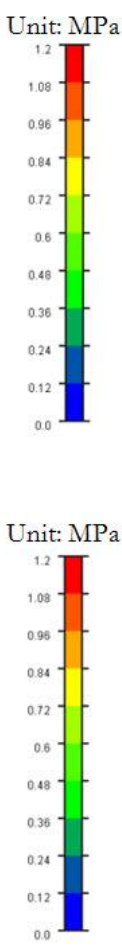
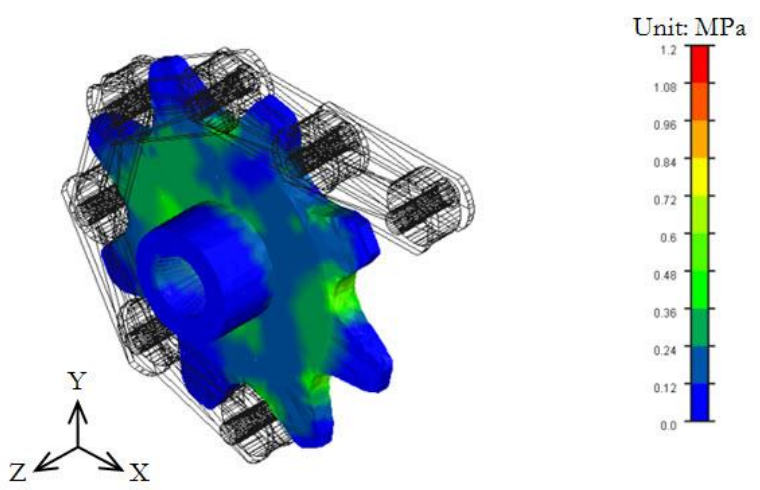

(b)

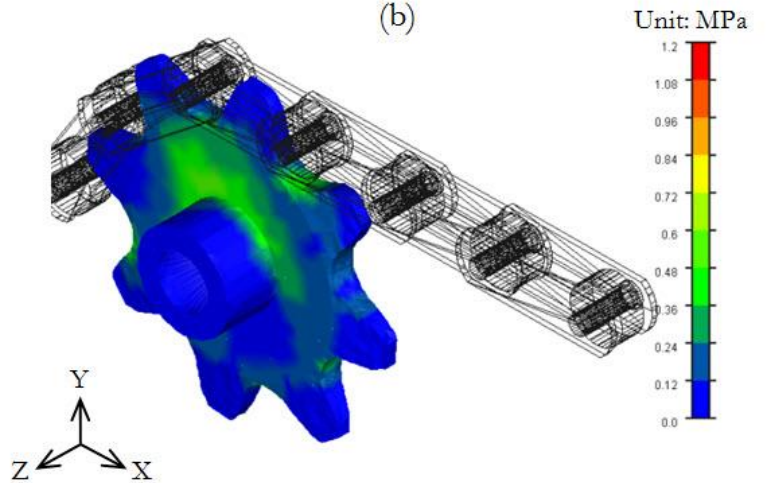

(d)

Fig. 9. The sequent images of von Mises stress developing on a sprocket of a drive system at: (a) time $=$ $0.000 \mathrm{sec},(\mathrm{b})$ time $=0.1076 \mathrm{sec}$, (c) time $=0.4449 \mathrm{sec}$, and (d) time $=0.7755 \mathrm{sec}$.

\section{Roller Chain Drive System Analysis}

The roller chain drive system which was analyzed and validated in previous sections had a chain link of the tight side was parallel to the slack side. The angle between chain links on the tight side and slack side had measured of 0 degrees. The stress which was developed on the drive system advanced to perceive failure and deformable behaviors on both a roller chain and a sprocket. There are many angles between a chain link of a tight and a slack side which found in the drive system of production lines had been interested in studying failure behaviors. These angles caused the roller chain drive system were complicated to solve by an analytical method. This research additionally proposed four angles to simulate by the integration of FEM and MBS which composed of $45^{\circ}, 90^{\circ}, 135^{\circ}$ and $180^{\circ}$. Figure 10 shows FE models of a roller chain meshes with a sprocket in any angle between chain links of a tight side and slack side. The sprocket had been also interested on the failure behavior by the different angle between a tight side and slack side of chain links as same as the roller chain analysis. The simulation models of the sprocket analysis are shown in Fig. 11.

The maximum stress and strain develop on the roller chain drive system which arranges different angles are shown in Fig. 12 and Fig. 13, respectively. The maximum von Mises stress and strain occurred on cylindrical pins of the roller chain under every angle operation. In the same angles of the roller chain analysis, the sprocket happen the maximum von Mises stress are shown in Fig. 14. Table 2 describes the maximum von Mises stress and strain which develops on components of the roller chain drive system under each angle of chain wrapping. The drive system which the chain meshed a sprocket with an angle of $90^{\circ}$ under the same operating condition had the large of the maximum von Mises stress developing on the roller chain. Consequently, the production line should avoid construction of the drive system by this angle of the roller chain. The wrapping angle of $45^{\circ}$ was the suitable angle of the roller chain to change direction 


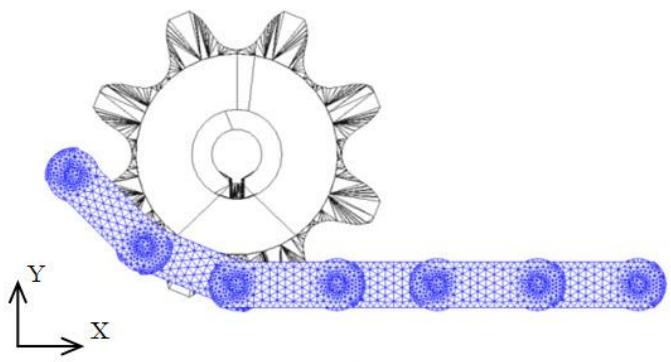

(a)

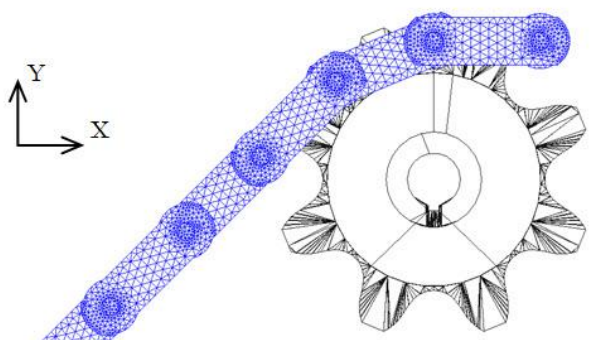

(c)

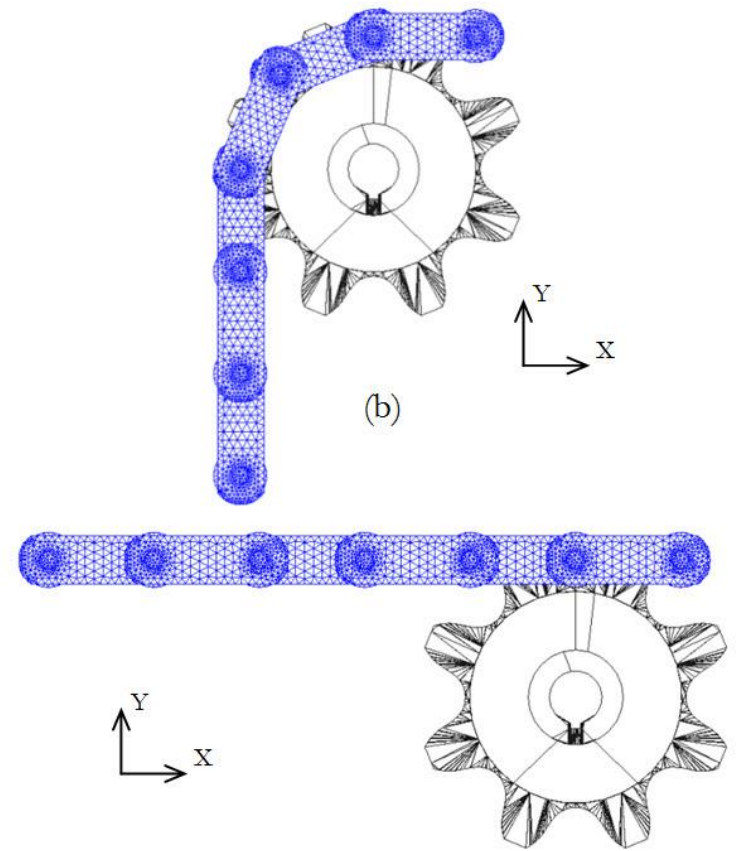

(d)

Fig. 10. The roller chain analysis for an angle chain link between tight and slack side of: (a) $45^{\circ}$, (b) $90^{\circ}$, (c) $135^{\circ}$, and (d) $180^{\circ}$.

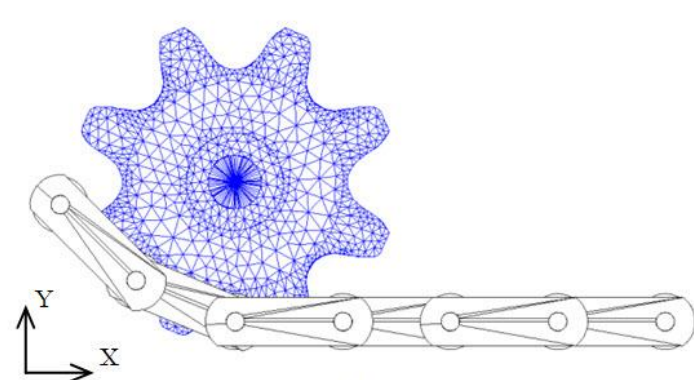

(a)

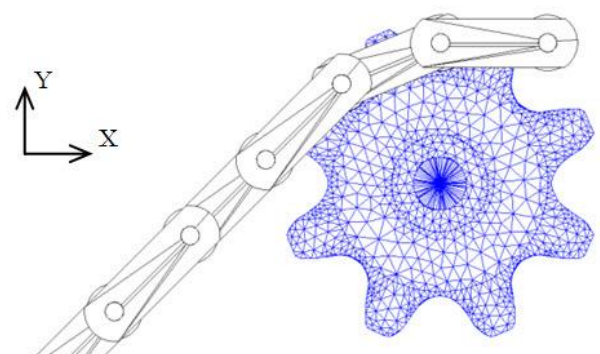

(c)

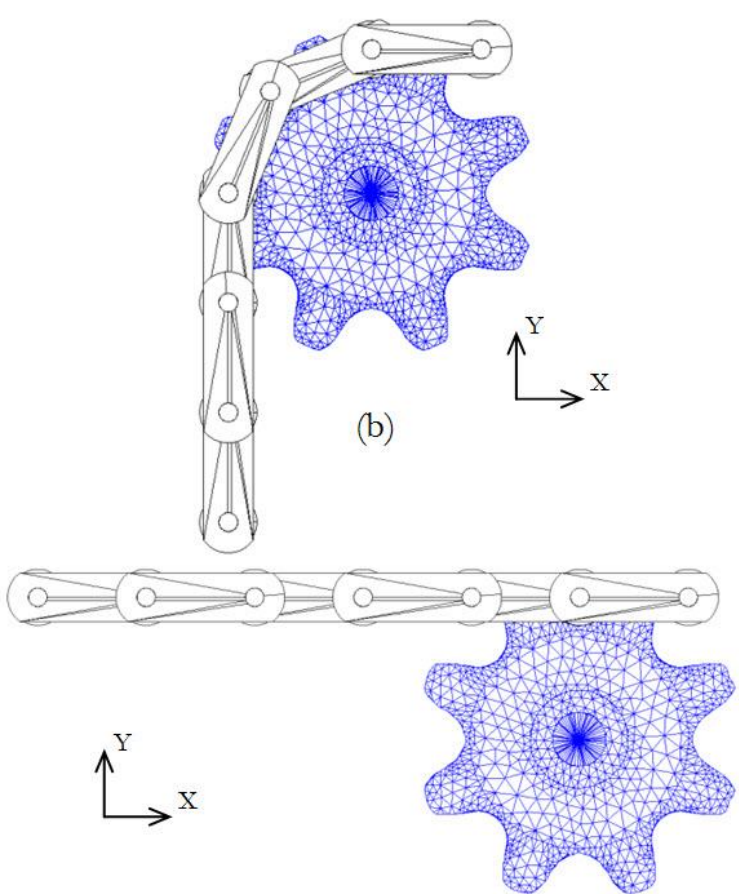

(d)

Fig. 11. The sprocket analysis for an angle chain link between tight and slack side of: (a) $45^{\circ}$, (b) $90^{\circ}$, (c) $135^{\circ}$, and (d) $180^{\circ}$. 


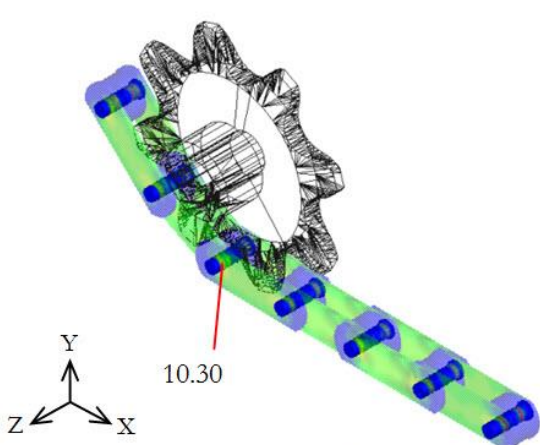

(a)

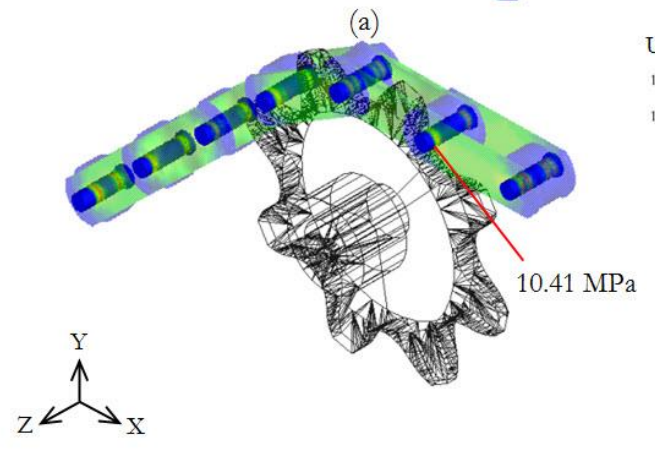

(c)

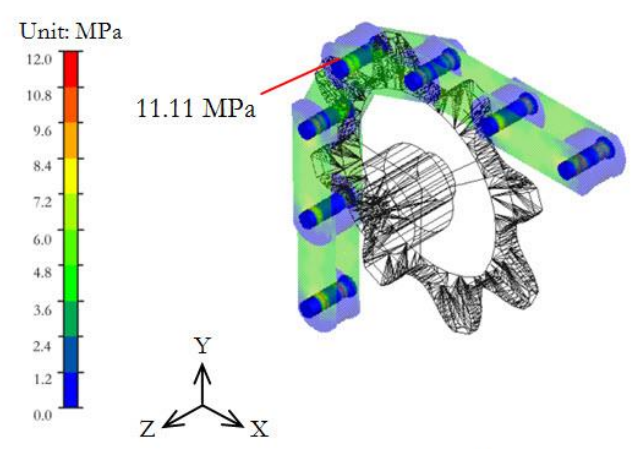

(b)
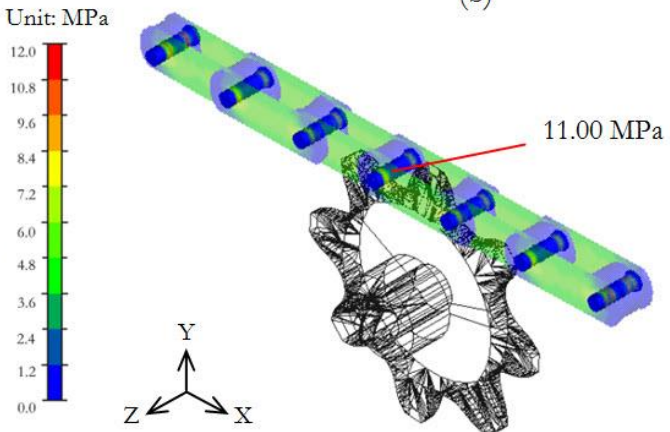

(d)
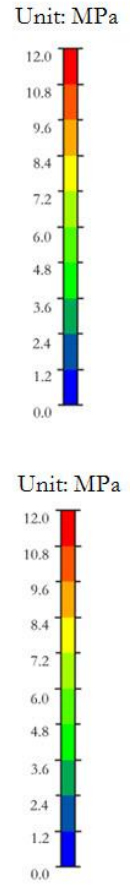

Fig. 12. The maximum von Mises stress developing on a roller chain of the drive system with the wrapping angles of: (a) $45^{\circ}$, (b) $90^{\circ}$, (c) $135^{\circ}$, and (d) $180^{\circ}$.

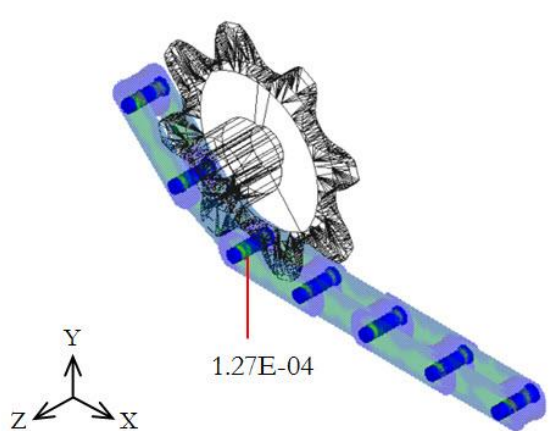

(a)

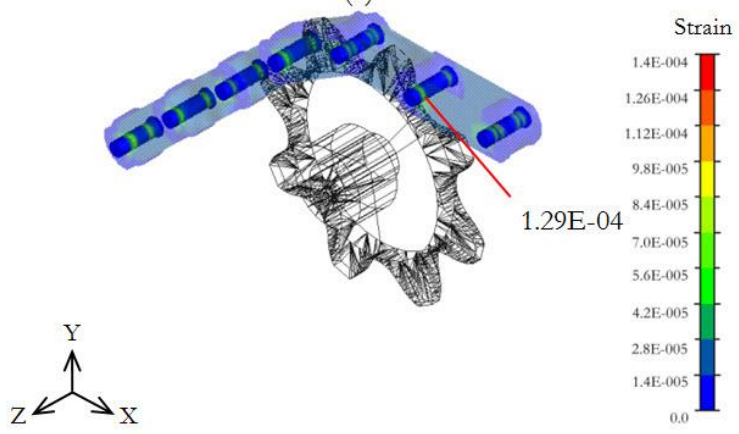

(c)
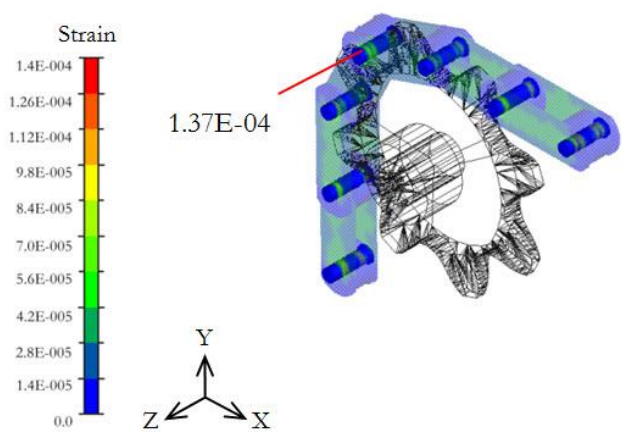

(b)

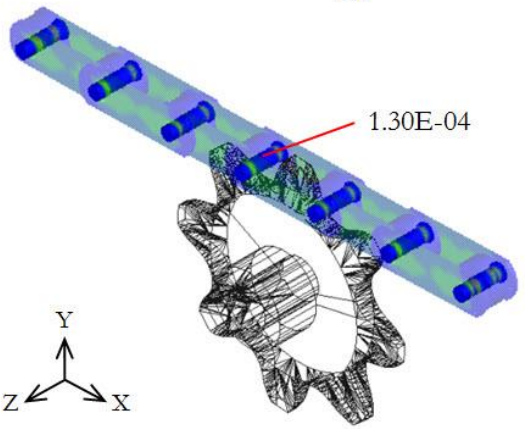

(d)
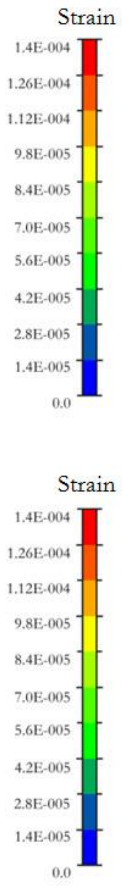

Fig. 13. The maximum strain developing on a roller chain of the drive system with the wrapping angle of: (a) $45^{\circ}$, (b) $90^{\circ}$, (c) $135^{\circ}$, and (d) $180^{\circ}$. 


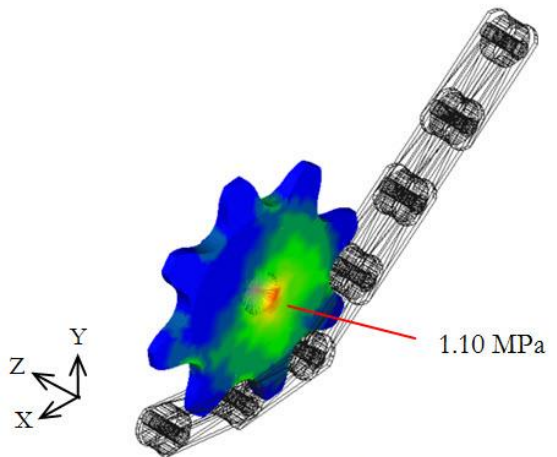

(a)

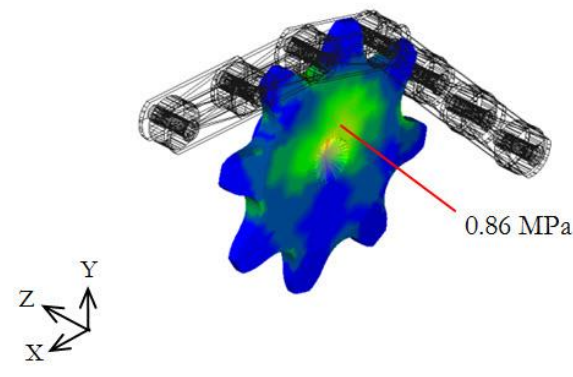

(c)
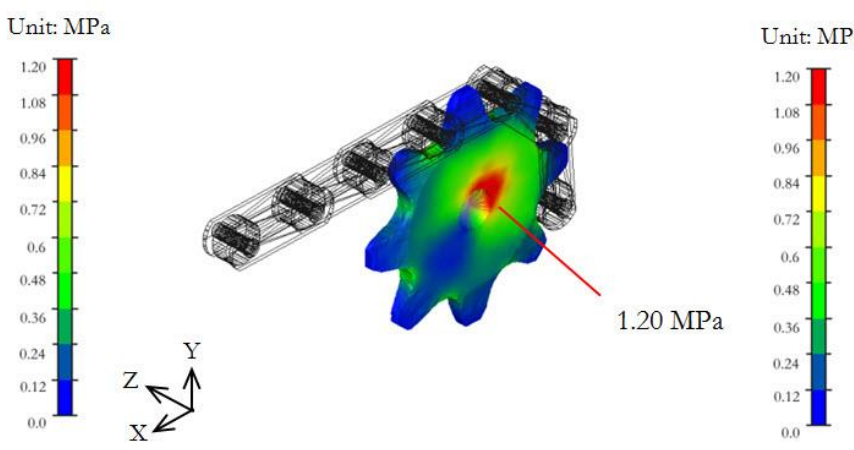

(b)

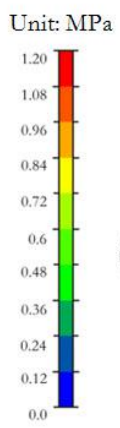

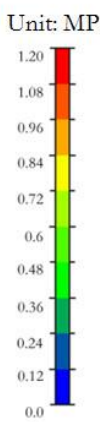

(d)

Fig. 14. The maximum von Mises stress developing on a sprocket of the drive system with the wrapping angle of: (a) $45^{\circ}$, (b) $90^{\circ}$, (c) $135^{\circ}$, and (d) $180^{\circ}$.

Table 2. The maximum stress and strain developing on the chain drive system.

\begin{tabular}{ccccc}
\hline \multirow{2}{*}{$\begin{array}{c}\text { Chain } \\
\text { wrapping angle } \\
\text { (degree) }\end{array}$} & \multicolumn{2}{c}{ Cylindrical pin } & \multicolumn{2}{c}{ Sprocket } \\
\cline { 2 - 5 } & Stress (MPa) & Strain $\left(\times \mathbf{1 0}^{-4}\right)$ & Stress (MPa) & Strain $\left(\times \mathbf{1 0}^{-4}\right)$ \\
\hline 0 & 11.05 & 1.33 & 1.11 & 0.14 \\
45 & 10.30 & 1.27 & 1.10 & 0.13 \\
90 & 11.11 & 1.37 & 1.20 & 0.15 \\
135 & 10.41 & 1.29 & 0.86 & 0.10 \\
180 & 11.00 & 1.30 & 0.18 & 0.02 \\
\hline
\end{tabular}

because it was happened the minimum von Mises stress. The maximum stress developed in the area which was close to the shaft hole of the sprocket more than the sprocket tooth. There was investigated at the red color area (Fig. 14b) which was instead the maximum von Mises stress happening in the sprocket. The wrapping angle of $90^{\circ}$ induced the large von Mises stress happened on a sprocket while the wrapping angle of $180^{\circ}$ happened the small von Mises stress.

The large von Mises stress acted not more than the maximum allowable stress then the failure of the chain drive systems in this study came from the fatigue. The different frequency which impact forces happens on a sprocket and rollers by the different wrapping angle of the roller chain during the rotation of the drive system as shown by graphs in Fig. 15. The fatigue failure of moving parts based on stress and strain always depended on both frequency and magnitude of them [21, 22]. There was the maximum value of von Mises stress and strain that developed on components of the drive system should gather to consider the usage lift. It was easy to investigate impacted frequency because the impact force developed following the number of sprocket tooth which contacted the chain rollers. Furthermore, the integrating between FEM and MBS simulation in this research could help to investigate a time period of each impact force distinctively. The drive system with the wrapping angle of $90^{\circ}$ had the most of maximum impact force magnitude. The wrapping angle of $45^{\circ}$ and $135^{\circ}$ had an equal time period which less than the wrapping angle of $90^{\circ}$. Consequently, the frequency of impact force occurring of $45^{\circ}$ and $135^{\circ}$ wrapping angle were more than the wrapping angle of $90^{\circ}$. The minimum magnitude and frequency of impact forces which 
developed on chain rollers occurred by the wrapping angle of $180^{\circ}$. The drive system with chain links angle between tight and slack side of $180^{\circ}$ had the maximum endurance limit for usage in this research. This wrapping angle often was met in the processing line where a distance between two long sprockets. It was installed between these sprockets to protect the sagging of chain.

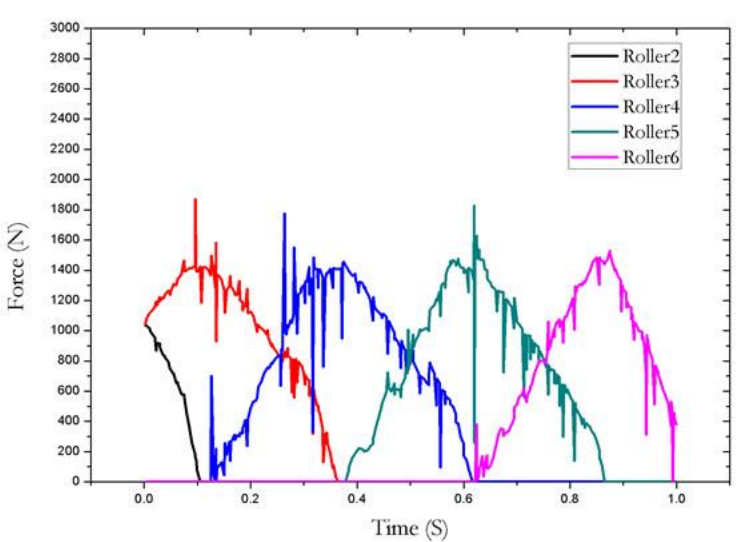

(a)

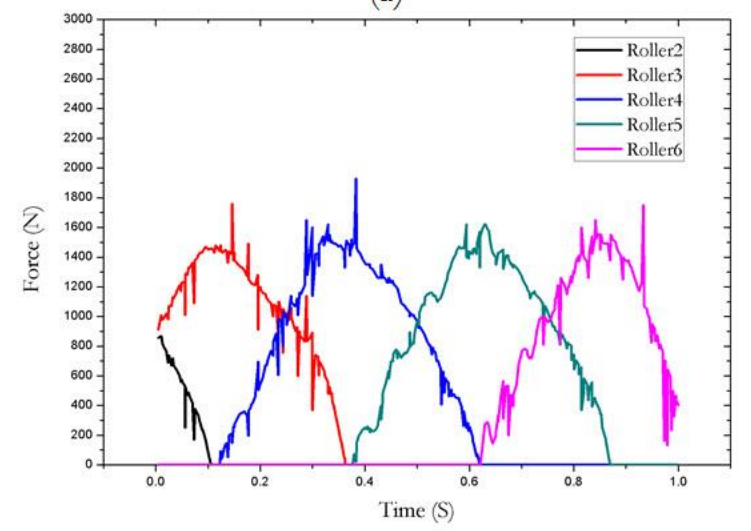

(c)

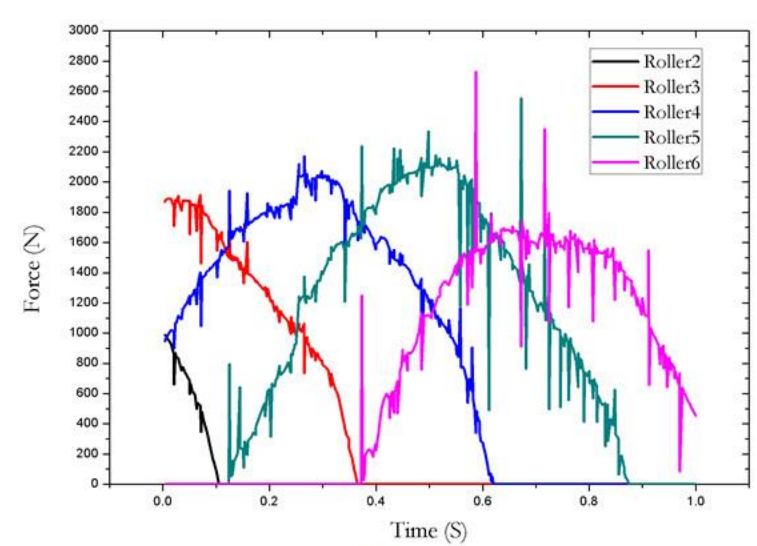

(b)

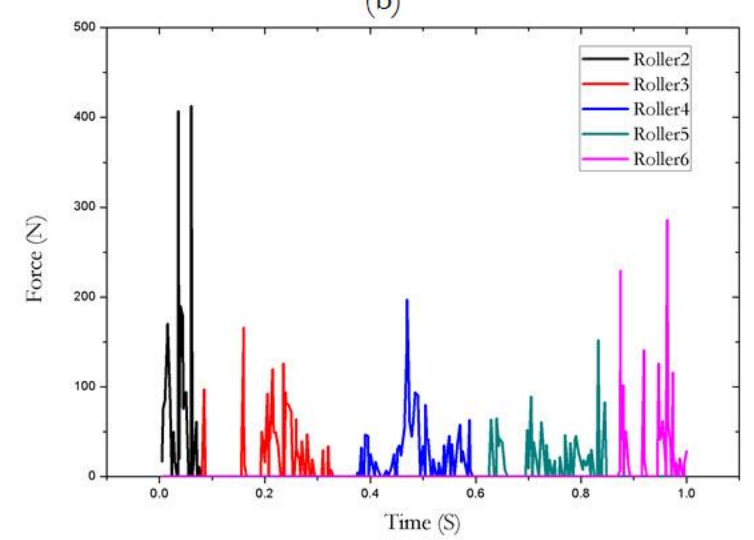

(d)

Fig. 15. The impact force between chain rollers and sprocket tooth in the drive system with chain wrapping angles of: (a) $45^{\circ}$, (b) $90^{\circ}$, (c) $135^{\circ}$ and (d) $180^{\circ}$.

\section{Conclusion}

The dynamic load distribution in the roller chain drive system was simulated with an integration of FEM and MBS. The integration of simulation method was compared with analytical method and obtained an average error of $14.26 \%$. The von Mises stress and strain developed on the drive system components were an advance result of the integration of simulation method which could use to analyze the strength of system under dynamic simulation. The different angle of chain wrapping on sprockets in the drive system affected to the von Mises stress that developed on components of the system. The large von Mises stress happened on the cylindrical pins of roller chains which wrapped a sprocket with an angle of $90^{\circ}$ while the wrapping angle of $45^{\circ}$ had a small von Mises stress. The roller chain would have been damaged by the fatigue failure before the sprocket. It had been encouraged by the magnitude of stress on the roller chain which was more than the sprocket about 9.2 times. The suitable wrapping angle of the roller chain for the sprocket was $180^{\circ}$ while $90^{\circ}$ still was a severe angle. The frequency of impact force that happened along the cycle of the sprocket rotation could express by the time period. The small time period would have the large frequency of the impact force occurring. The wrap angle of $45^{\circ}$ and $135^{\circ}$ happened frequency more than the wrapping angle of $90^{\circ}$ even though the magnitude of the maximum impact force less than the wrapping angle of $90^{\circ}$. Therefore, both magnitude and frequency would be considered the fatigue failure of the drive system. The small magnitude and frequency of impact forces were the chain wrapping of $180^{\circ}$. This simulation results expressed the effect of the wrapping angle of the roller chain in the drive system. The 
coupling method between FEM and MBS would be useful and advance to design and predict the strength of the roller chain drive system for the producing line in a further work.

\section{References}

[1] J. L. Wright, "Roller chain drives," in Standard Handbook of Chain, 2nd ed. Florida: CRC Press, 2006, ch. 5, pp. 129-175.

[2] R. G. Budynas and J. K. Nisbett, "Gear-general," in Shigley's Mechanical Engineering Design, 9th ed. New York: McGraw-Hill, 2008, ch. 13, pp. 674-714.

[3] M. Sujata, M. A. Venkataswamy, M. A. Parameswara, and S. K. Bhaumik, "Failure analysis of conveyor chain links," Eng Fail. Anal., vol. 13, pp. 914-924, 2006.

[4] R. N. Mohammad and M. M. Kurt, "Analysis of sprocket load distribution," Mech. Mach. Theory, vol. 18, no. 5, pp. 349-356, 1983.

[5] R. N. Mohammad and M. M. Kurt, "Analysis of roller chain sprocket pressure angles," Mech. Mach. Theory, vol. 19, no. 2, pp. 197-203, 1984.

[6] S. L. Pedersen, J. M. Hansen, and J. A. C. Ambrosio, "A roller chain drive model including contact with guide-bars," Multibody Syst. Dyn., vol. 12, pp. 258-301, Feb. 2004.

[7] S. L. Pedersen, "Simulation and analysis of roller chain drive systems," Ph.D. thesis, Dept. Mech. Eng., DTU, Lyngby, Denmark, 2004.

[8] S. L. Pedersen, "Model of contact between rollers and sprockets in chain-drive systems," Arch. Appl. Mech., vol. 74, pp. 489-508, Apr. 2005.

[9] N. Fuflede and J. J. Thomsen, "Kinematics of roller chain drives-exact and approximate analysis," Mech. Mach. Theory, vol. 100, pp. 17-32, Jun. 2016.

[10] C. Yenti, S. Phongsupasamit, and C. Ratanasumawong, "Analytical and experimental investigation of parameters affecting sliding loss in a spur gear pair," Engineering Journal, vol. 17, no. 1, pp. 79-93, Jan. 2013.

[11] M. Cali, G. Sequenzia, S. M. Oliveri, and G. Fatuzzo, "Meshing angle evaluation of silent chain drive by numerical analysis and experiment test," Mechanica, vol. 51, pp. 475-489, Mar. 2016.

[12] M. Wallin, A. K. Aboubakr, P. Jayakumar, M. D. Letherwood, D. J. Gorsich, A. Hamed, and A. A. Shabana, "A comparative study of joint formulation: application to multibody system tracked vihecles," Nonlinear Dyn, vol. 74, pp. 783-800, Aug. 2013.

[13] Y. Wang, D. Ji, and K. Zhan, "Modified sprocket tooth profile of roller chain drive," Mech. Mach. Theory, vol. 70, pp. 380-393, Dec. 2013.

[14] A. Bravo, D. Koffi, L. Toubal, and F. Erchiqui, "Lift and damage mode modeling applied to plastic gears," Eng. Fail. Anal., vol. 58, pp. 113-133, Dec. 2015.

[15] S. M. Bosnjak, M. A. Arsic, N. D. Zrnic, Z. D. Odanovic, and M. D. Dordevic, "Failure analysis of the stacker crawler chain link," Procedia Eng., vol. 10, pp. 2244-2249, 2011.

[16] F. E. Udwad and A.D. Schutte, "Equation of motion for general constrained systems in Lagrangian mechanics," Acta. Mech., vol. 213, pp. 111-129, Aug. 2010.

[17] F. P. Beer, E. R. Johnston Jr., J. T. Dewoft, and D. F. Mazurek, "Stress and strain-axial loading," in Mechanics of Materials, 5th ed. New York: McGraw-Hill, 2009, ch. 2, pp. 46-130.

[18] R. R. Craig and M. C. C. Bampton, "Coupling of structures for dynamic analyses," ALAA Journal, vol. 6, no. 7, pp. 1113-1119, Jul. 1968.

[19] J. B. McConville, "Appendix I - Principle Adams modeling elements," in Introduction to Mechanical System Simulation Using Adams. USA: SDE Publications, 2015, pp. 129-148.

[20] C. W. Gear, "The automatic integration of ordinary differential equations," Commun. $A C M$, vol. 14, no. 3, pp. 176-179, Mar. 1971.

[21] Y. L. Lee, J. Pan, R. Hathaway, and M. Barkey, "Stress-based fatigue analysis and design," in Fatigue testing and analysis, Massachusetts: Elsevier Inc., 2005, ch. 4, pp. 103-180.

[22] Y. L. Lee, J. Pan, R. Hathaway, and M. Barkey, "Strain-based fatigue analysis and design," in Fatigue Testing and Analysis, Massachusetts: Elsevier Inc., 2005, ch. 5, pp. 184-236. 